clinical skills under such artificial conditions may not be valid or reliable.

The reliability of essays as part of the exam is questioned by Professor Trethowan. Drs Aveline and Thompson feel they have merit because they can test ability to communicate, ability to show critical judgement and test a wider area of knowledge. One surely must agree with Professor Trethowan that there are better ways to test the ability to communicate and this is not what the exam is for. He suggests a modification to a number of 'short-answer' questions. I should like to suggest a different type of replacement for the essay in Part II of the MRCPsych. The research option has been unpopular, and in my personal experience requires much more work than the small part of the exam it replaces. However, I feel that a valuable aspect of it is the encouragement to study a wider area of the literature on a specific topic and the encouragement to think about how a problem in psychiatry might be approached. I propose a modification of this option to a compulsory dissertation of, say, 5,000-7,000 words. This need not include any actual research work or results (though could if a candidate so wished) but would be an extensive review of an area of psychiatric literature of interest to that candidate, with reference to some unresolved problems in that area and perhaps suggestions as to how they might be tackled. In the instance of a candidate interested in psychotherapy or behaviour therapy, he or she might include a discussion of a particular form of therapy and illustrate this with a case or cases treated personally. The titles for such dissertations could, if it was felt necessary, be approved by either an examinations committee or the candidate's local Professor. I believe this type of innovation, instead of essay questions, would be the best way to test the ability to appreciate a wider area of knowledge and the ability to show critical judgement. In addition, it would be carried out in the absence of 'exam nerves', might stimulate people to think more clearly about problems and could stimulate research. For overseas candidates who may find the task of writing essays a greater task than others, it would allow more time for them to express themselves to the level of which they are really capable.

Holywell Hospital

Antrim

STEPHEN J. COOPER

\section{Videotapes on psychiatric subjects}

Dear Sirs

Professors Seager and Goldberg (Bulletin, November $1982,6,203-4)$ are to be commended for pioneering the use of videotape in training young psychiatrists to give ECT and for making their tapes available.

Inevitably these first productions are not wholly satisfactory and should be viewed critically. The Sheffield videotape is the better.
I am particularly concerned that the Manchester tape is offered for self-teaching for it contains errors of fact and technique. The tapes will be a useful aid to learning but not a substitute for full theoretical and practical training by those experienced in ECT. They ought to be discussed with learners when they are seen.

No doctor should administer the treatment unsupervised until the responsible consultant is satisfied with his knowledge and skill.

\section{Belgrave Square}

John PIPPard

\section{London SWIX 8PG}

\section{Dear SiRS}

The recent flurry of publication, discussion and publicity has ensured that most doctors are alerted to the problem of alcoholism. Unfortunately some doctors, particularly those in training, are still unsure about what to do when confronted with a problem drinker. The result of this uncertainty is, not infrequently, frustration, irritation and despair for both the doctor and the patient.

The Department of Mental Health at the Queen's University, Belfast, has recently produced a new videotape, which is especially appropriate for use with medical students and junior medical staff, in either hospital or general practice.

The tape is called 'The Alcohol Dependence SyndromeA Psychological Approach' (colour, $47 \mathrm{mins}$ ). It presents guidelines on the assessment of the problem and a model for understanding approaches (cognitive, psychodynamic and existential). The tape follows the progress of one young man through his time in the regional treatment centre, and deals realistically, but enthusiastically, with the often daunting process of rehabilitation.

The programme may be copied on to your own blank $U$ matic, VHS or Betamax cassette at a cost of $£ 15$. It is available from Mr Brian Patton, Audio-Visual Unit, Department of Mental Health, The Queen's University, Belfast, 97 Lisburn Road, Belfast.

\section{Belfast City Hospital} Belfast

JOHN T. ALDERDICE

\author{
Psychology of nuclear disarmament \\ DeAr SIRS \\ I found Neill Simpson's letter (Bulletin, November 1982, \\ $6,202-3)$ puzzling and on closer inspection disturbing in its \\ form. The first paragraph sets an analogy, novel to me, \\ between the deterrent effect of nuclear weapons and addic- \\ tion to drugs, only to knock it down immediately. The \\ second paragraph leads us from this analogy to a considera- \\ tion of the fact that information is sometimes withheld from
}

